\title{
APLIKASI QUALITY FUNGTION DEPLOYMENT (QFD) PADA PENINGKATAN MUTU SUWAR SUWIR TAPE HANDAYANI 82 DI KABUPATEN BONDOWOSO
}

The Application of Quality Fungtion Deployment (QFD) in Improving Quality of "Suwar Suwir” Tape Handayani 82 in Bondowoso Regency

\author{
Ade Galuh Rakhmadevi ${ }^{1) *}$, Sih Yuwanti ${ }^{2)}$, Bambang Herry Purnomo ${ }^{2)}$ \\ ${ }^{1)}$ Magister Teknologi Agroindustri, Fakultas Teknologi Pertanian, Universitas Jember \\ ${ }^{2)}$ Fakultas Teknologi Pertanian, Universitas Jember \\ Jl. Kalimantan No. 37 Kampus Tegalboto Jember 68121, Indonesia \\ *E-mail : rakhmadevi@gmail.com
}

\begin{abstract}
The intensity industrial competition required Tape Handayani 82 factory to develop its quality to compete in the market. The development of quality could be done by searching information about quality attribute of suwar suwir as costumer expectation. The purpose of this research was to identify quality attribute of suwar suwir and technical response requiring improvement, which could fulfill costumer expectation. Data was taken by distributing questionnaire to 65 respondents with non probability sampling method at 4 subdistrict in Bondowoso Regency, and interview to the producer of suwar suwir "Tape Handayani 82". The research result showed that the quality attributs that needed to be improved were the fixed composition, the self life of the product, the fixed texture, the label of composition, the suitability of the product with the label, the taste variation and packaging form. The technical responses which improved in relation to quality improvement were the composition of the additional materials, the composition of the raw material, the maturity of the tape, the heating temperature, the heating time, the acidity level the tape, the stirring technique, the mixing time, the primary packaging type, smoothing technique, chilling time and fiber removal. The target value to the technical response of the Handayani 82 factory was less than the bencmark. This mean that suwar suwir of Tape Handayani 82 has not met the target in fulfilling the quality of suwar suwir as costumer expectation.
\end{abstract}

Keywords: quality, suwar suwir, quality function deploment (QFD), customer

\section{PENDAHULUAN}

Kabupaten Bondowoso merupakan salah satu kabupaten di Jawa Timur yang terkenal akan produksi singkong yang memiliki potensi tinggi untuk diolah menjadi berbagai produk olahan diantaranya tape singkong. Tape singkong merupakan produk hasil fermentasi yang memiliki umur simpan sekitar $2-3$ hari sehingga perlu dilakukan berbagai upaya diversifikasi produk untuk meningkatkan nilai jual, salah satunya adalah dengan membuat suwar suwir yang dapat dikembangkan menjadi salah satu produk unggulan selain tape singkong di Kabupaten Bondowoso karena umur simpannya yang cukup panjang dengan tekstur yang keras dan rasa yang manis.

Sejalan dengan perubahan pola pikir masyarakat yang berkembang di era perdagangan bebas, produk suwar suwir Kabupaten Bondowoso dihadapkan pada masalah utama yaitu mutu produk. Menurut Magutu et al. (2010) mutu produk merupakan faktor kunci dalam meningkatkan daya saing perusahaan di era global. UNIDO (2006) secara singkat menyatakan bahwa produk bermutu adalah produk yang mampu memenuhi kebutuhan dan harapan pelanggan. Konsep tersebut menegaskan bahwa upaya perbaikan mutu produk tidak cukup dilakukan dengan 
meningkatkan keunggulan produk secara kompetitif saja tanpa memperhatikan harapan pelanggan. Mutu produk merupakan unsur utama dalam bauran pemasaran (marketing mix), yaitu produk, harga, promosi, dan saluran distribusi yang dapat meningkatkan volume penjualan dan memperluas pangsa pasar perusahaan (Nasution, 2001). Perbaikan aspek mutu diharapkan dapat menjamin distribusi, ketersediaan produk, jangkauan pemasaran yang lebih luas sehingga secara langsung dapat meningkatkan daya saing yang pada akhirnya industri suwar suwir di Kabupaten Bondowoso mampu berkembang dan berkelanjutan.

Perusahaan "Tape Handayani 82" merupakan salah satu perusahaan di Kabupaten Bondowoso yang memproduksi suwar suwir sebagai salah satu produk olahan dari tape. Persaingan yang ketat dalam dunia industri menuntut perusahaan untuk melalukan berbagai upaya peningkatan daya saing, salah satunya adalah dengan peningkatan mutu suwar suwir. Harapan dan keinginan pelanggan belum diketahui secara pasti sehingga dipandang perlu untuk melakukan analisis untuk menangkap keinginan pelanggan dengan menggunakan analisis Quality Function Deployment (QFD).

Tujuan dari penelitian ini adalah untuk mengetahui atribut mutu dari suwar suwir dan respon teknis yang memerlukan perbaikan yang sesuai dengan harapan pelanggan. Perbaikan yang dilakukan terhadap atribut mutu dan respon teknis diharapkan mampu meningkatkan volume penjualan dari suwar suwir.

\section{METODE PENELITIAN}

\section{Bahan}

Suwar suwir yang digunakan dalam penelitian ini adalah Suwar suwir produksi "Tape Handayani 82' Bondowoso. Produk pesaing yang digunakan yaitu merk Primadona, Mutiara
Rasa dan Sari madu yang berasal dari Jember.

\section{Metode Analisis}

Pengambilan data dilakukan dengan cara penyebaran kuesioner pada 65 responden dengan menggunakan teknik non probability sampling di 4 kecamatan yaitu Kecamatan Grujugan, Kecamatan Bondowoso, Kecamatan Tegalampel, dan Kecamatan Wonosari. Wawancara dilakukan dengan produsen suwar suwir Tape Handayani 82 dan wawancara dengan produsen suwar suwir Tape Handayani 82 untuk mengetahui respon teknis dari masing-masing tahapan proses pengolahan suwar suwir.

Data yang telah diperoleh selanjutnya dianalisis menggunakan metode Quality Fungtion Deployment (QFD). Metode QFD bertujuan untuk mengetahui harapan pelanggan akan atribut - atribut mutu yang diinginkan oleh pelanggan dan mengetahui respon teknis yang perlu diperbaiki. Analisis data terdiri atas:

a. Kebutuhan pelanggan terdiri atas sejumlah kebutuhan dan keinginan pelanggan terhadap atribut mutu suwar suwir. Kebutuhan pelanggan meliputi tingkat kepentingan pelanggan (importance to customer) yang menunjukkan tingkat kepentingan suatu atribut mutu terhadap kebutuhan pelanggan dan tingkat kepuasan pelanggan pada atribut mutu tersebut;

b. Respon teknis meliputi beberapa respon teknis yang berpengaruh terhadap atribut mutu yang diinginkan oleh pelanggan;

c. Matriks perencanaan meliputi tingkat kepentingan produk bagi pelanggan, tingkat kepuasan pelanggan terhadap suwar suwir produksi Tape 82 kabupaten Bondowoso, tingkat kepuasan pelanggan terhadap pesaing, goal, improvement ratio, sales point, raw weight, normalized raw weight; 
d. Bagian D (Matrix Relationship), mengenai kekuatan hubungan antara elemen-elemen yang terdapat pada bagian-bagian persyaratan teknis (matriks) dan kebutuhan pelanggan (matriks A) yang dipengaruhinya;

e. Bagian E (Korelasi Persyaratan Teknis) menunjukkan korelasi antara persyaratan teknis yang satu dan persyaratan-persyaratan lain yang terdapat di matriks;

f. Matriks Target Persyaratan Teknis) yang meliputi 3 (tiga) jenis informasi yaitu contribution (kontribusi), benchmarking (patok duga), targetting.

\section{HASIL DAN PEMBAHASAN}

\section{Identifikasi Atribut Mutu}

Menurut Tjiptono (2008), atribut produk adalah unsur-unsur produk yang dipandang penting oleh pelanggan dan dijadikan dasar pengambilan keputusan pembelian. Ditengah persaingan usaha yang semakin ketat, perusahaan dituntut untuk senantiasa menjaga dan meningkatkan mutu dari produk yang dihasilkan.

Berdasarkan hasil penyebaran kuesioner pada 65 responden, diperoleh 18 atribut mutu yang diharapkan oleh pelanggan suwar suwir yaitu warna, tekstur, rasa, aroma, adanya variasi warna, variasi rasa, komposisi tetap, label komposisi, label halal, kesesuaian produk dengan label, umur simpan, rasa dan aroma tetap, tekstur tetap, kemudahan memperoleh produk, adanya nomor layanan, promosi, bentuk kemasan, dan variasi ukuran kemasan.

\section{Tingkat Kepentingan dan Kepuasan Pelanggan}

Dwi et al. (2012) menyatakan bahwa tingkat kepentingan pelanggan menunjukkan tingkat kepentingan terhadap kebutuhan pelanggan. Tingkat kepentingan pelanggan disusun sebagai tindak lanjut untuk mengatahui seberapa besar kepentingan dari 18 atribut mutu suwar suwir terhadap kualitas suwar suwir Tape Handayani 82 yang diharapkan oleh pelanggan.

Kepuasan adalah tingkat perasaan seseorang setelah membandingkan kinerja produk (hasil) yang dirasakan dengan harapannya (Abdullah et al., 2012). Tingkat kepuasan merupakan penilaian yang subyektif dari hasil yang diperolehnya. Jika pelanggan merasa sesuai dengan yang dialami dan dirasakannya, bahkan mungkin melebihi harapannya maka sudah dapat dipastikan pelanggan akan merasa puas. Tingkat kepuasan pelanggan berhubungan erat dengan seberapa besar suatu produk mampu memenuhi/menjawab keinginan pelanggan.

Tabel 1. Tingkat kepentingan pelanggan terhadap atribut suwar suwir Tape Handayani 82

\begin{tabular}{|c|c|c|}
\hline $\begin{array}{c}\text { Dimensi } \\
\text { Mutu }\end{array}$ & Atribut mutu & $\begin{array}{c}\text { Kepentingan } \\
\text { Pelanggan } \\
\end{array}$ \\
\hline \multirow{4}{*}{ Performa } & Warna & 3 \\
\hline & Tekstur & 5 \\
\hline & Rasa & 5 \\
\hline & Aroma & 3 \\
\hline \multirow{2}{*}{ Fitur } & Variasi warna & 3 \\
\hline & Variasi rasa & 4 \\
\hline Keandalan & $\begin{array}{l}\text { Komposisi tidak } \\
\text { berubah }\end{array}$ & 5 \\
\hline \multirow{3}{*}{ Konfirmasi } & Label komposisi & 5 \\
\hline & Label halal & 5 \\
\hline & $\begin{array}{l}\text { Keseuaian produk } \\
\text { dengan label }\end{array}$ & 5 \\
\hline \multirow{3}{*}{ Daya tahan } & Umur simpan produk & 5 \\
\hline & Rasa dan aroma tetap & 5 \\
\hline & Tekstur tetap & 5 \\
\hline \multirow{3}{*}{ Pelayanan } & $\begin{array}{l}\text { Kemudahan } \\
\text { memperoleh produk }\end{array}$ & 3 \\
\hline & $\begin{array}{l}\text { Adanya nomor } \\
\text { layanan }\end{array}$ & 4 \\
\hline & Promosi & 4 \\
\hline \multirow[b]{2}{*}{ Estetika } & Bentuk kemasan & 3 \\
\hline & $\begin{array}{l}\text { Variasi ukuran } \\
\text { kemasan }\end{array}$ & 4 \\
\hline
\end{tabular}


Tabel 1 menunjukkan tingkat kepentingan terhadap 18 atribut mutu yang diaharapkan oleh pelanggan suwar suwir. Atribut mutu yang memiliki nilai tingkat kepentingan 5 (sangat penting) adalah tekstur, rasa, komposisi tetap, label komposisi, label halal, kesesuaian produk dengan label, umur simpan, rasa dan aroma tetap, dan tekstur tidak berubah.

\section{a. Tekstur}

Atribut tekstur merupakan atribut mutu pada suwar suwir yang diinginkan oleh pelanggan sehingga merupakan faktor yang sangat penting yang harus ada pada suwar suwir. Pelanggan menghendaki tekstur yang keras di permukaan tetapi lembut saat dimakan.

b. Rasa

Pelanggan akan memilih dan setia pada suatu produk, jika produk tersebut memiliki rasa yang enak dan memiliki ciri khas dibandingkan produk lain yang sejenis.

c. Komposisi tetap

Suatu produk yang dibuat dengan menggunakan komposisi yang tetap/tidak mudah berubah akan meningkatkan kepercayaan dan kepuasan bagi pelanggan. Dengan komposisi yang tidak berubah, maka kualitas mutu produk akan tetap terjaga, dan umur simpan yang telah dapat diketahui dengan pasti.

d. Label komposisi

Salah satu informasi yang harus terdapat pada label suatu produk adalah label komposisi bahan-bahan yang digunakan dalam proses pembuatan suwar suwir. Dengan membaca label komposisi, pelanggan akan mengatahui secara pasti bahan - bahan yang digunakan dan hal ini dapat meningkatkan kepercayaan akan keamanan dari bahan-bahan yang digunakan.

Tabel 2. Tingkat kepuasan pelanggan suwar suwir Tape Handayani 82

\begin{tabular}{|c|c|c|c|c|c|}
\hline \multirow[b]{2}{*}{$\begin{array}{l}\text { Dimesi } \\
\text { Mutu }\end{array}$} & \multirow[b]{2}{*}{ Atribut mutu } & \multicolumn{4}{|c|}{ Tingkat Kepuasan Pelanggan } \\
\hline & & $\begin{array}{c}\text { Tape } \\
\text { Handayani } \\
82\end{array}$ & Primadona & $\begin{array}{l}\text { Sari } \\
\text { Madu }\end{array}$ & $\begin{array}{c}\text { Mutiara } \\
\text { Rasa }\end{array}$ \\
\hline \multirow{4}{*}{ Performa } & Warna & 3 & 2 & 3 & 3 \\
\hline & Tekstur & 3 & 3 & 3 & 3 \\
\hline & Rasa & 3 & 3 & 3 & 3 \\
\hline & Aroma & 3 & 3 & 3 & 3 \\
\hline \multirow{2}{*}{ Fitur } & Variasi warna & 3 & 3 & 2 & 3 \\
\hline & Variasi rasa & 3 & 4 & 3 & 3 \\
\hline Keandalan & $\begin{array}{l}\text { Komposisi tidak } \\
\text { berubah }\end{array}$ & 2 & 2 & 3 & 3 \\
\hline \multirow{3}{*}{ Konfirmasi } & Label komposisi & 2 & 2 & 3 & 3 \\
\hline & Label halal & 1 & 1 & 1 & 1 \\
\hline & $\begin{array}{l}\text { Keseuaian produk } \\
\text { dengan label }\end{array}$ & 2 & 3 & 3 & 3 \\
\hline \multirow{3}{*}{ Daya tahan } & Umur simpan & 2 & 3 & 3 & 3 \\
\hline & Rasa dan aroma tetap & 3 & 3 & 3 & 3 \\
\hline & Tekstur tidak berubah & 3 & 4 & 3 & 3 \\
\hline \multirow{3}{*}{ Pelayanan } & $\begin{array}{l}\text { Kemudahan } \\
\text { memperoleh produk }\end{array}$ & 3 & 3 & 3 & 3 \\
\hline & No layanan & 2 & 2 & 3 & 3 \\
\hline & Promosi & 2 & 2 & 2 & 2 \\
\hline \multirow{2}{*}{ Estetika } & Bentuk kemasan & 2 & 3 & 2 & 3 \\
\hline & Variasi ukuran kemasan & 3 & 3 & 2 & 3 \\
\hline
\end{tabular}




\section{e. Label halal}

Label halal merupakan salah satu faktor pada atribut mutu yang sangat penting ada pada suatu produk pangan. Hal ini disebabkan karena semakin banyaknya bahan tambahan makanan yang belum diketahui secara pasti kehalalannya.

f. Kesesuaian produk dengan label

Label merupakan suatu media untuk memberikan informasi yang lengkap bagi pelanggan akan suatu produk. Kesesuaian produk yang dikonsumsi dengan label yang tertera akan meningkatkan kepercayaan pelanggan sehingga secara langsung akan meningkatkan kepuasan bagi pelanggan.

g. Kesesuaian produk dengan label

Label merupakan suatu media untuk memberikan informasi yang lengkap bagi pelanggan akan suatu produk. Kesesuaian produk yang dikonsumsi dengan label yang tertera akan meningkatkan kepercayaan pelanggan sehingga secara langsung akan meningkatkan kepuasan bagi pelanggan. h. Rasa dan aroma tetap

Rasa manis dan memiliki aroma tape yang tetap pada suwar suwir merupakan atribut mutu yang dianggap sangat penting oleh pelanggan. Dengan perbandingan tape dan gula yang tetap akan meningkatkan kepercayaan pelanggan akan produk suwar suwir

i. Tekstur tetap

Atribut tekstur pada suwar suwir yang tetap atau tidak berubah juga merupakan atribut mutu berikutnya yang dianggap sangat penting oleh pelanggan. Tekstur yang diinginkan oleh pelanggan adalah tekstur yang keras di permukaan tetapi lembut saat dimakan.

Tingkat kepuasan pelanggan produk suwar suwir Tape Handayani 82 dan 3 produk pesaingnya yaitu suwar suwir Primadona, Sari Madu dan Mutiara Rasa dapat dilihat pada Tabel 2. Pelanggan dengan tingkat kepuasan 3 (puas) pada atribut mutu warna, rasa, tekstur, aroma,variasi warna, variasi rasa, rasa dan aroma yang tetap, tekstur yang tidak mudah berubah, kemudahan memperoleh produk dan variasi kemasan.

Tabel 3. Nilai goal/target masing - masing atribut suwar suwir

\begin{tabular}{|c|c|c|c|c|c|}
\hline \multirow[b]{2}{*}{ Atribut mutu } & \multicolumn{4}{|c|}{ Tingkat kepuasan pelanggan } & \multirow[b]{2}{*}{ Goal } \\
\hline & $\begin{array}{l}\text { Tape Handayani } \\
82\end{array}$ & Primadona & $\begin{array}{c}\text { Sumber } \\
\text { Madu }\end{array}$ & $\begin{array}{c}\text { Mutiara } \\
\text { Rasa }\end{array}$ & \\
\hline Warna & 3 & 2 & 3 & 3 & 3 \\
\hline Tekstur & 3 & 3 & 3 & 3 & 3 \\
\hline Rasa & 3 & 3 & 3 & 3 & 3 \\
\hline Aroma & 3 & 3 & 3 & 3 & 3 \\
\hline Variasi warna & 3 & 3 & 2 & 3 & 3 \\
\hline Variasi rasa & 3 & 4 & 3 & 3 & 4 \\
\hline Komposisi tetap & 2 & 2 & 3 & 3 & 3 \\
\hline Label komposisi & 1 & 2 & 3 & 3 & 3 \\
\hline Label halal & 1 & 1 & 1 & 1 & 1 \\
\hline $\begin{array}{l}\text { Keseuaian produk dengan } \\
\text { label }\end{array}$ & 2 & 3 & 3 & 3 & 3 \\
\hline Umur simpan & 2 & 3 & 3 & 3 & 3 \\
\hline Rasa dan aroma tetap & 3 & 3 & 3 & 3 & 3 \\
\hline Tekstur tidak berubah & 3 & 4 & 3 & 3 & 4 \\
\hline $\begin{array}{l}\text { Kemudahan memperoleh } \\
\text { produk }\end{array}$ & 3 & 3 & 3 & 3 & 3 \\
\hline No layanan & 2 & 2 & 3 & 3 & 3 \\
\hline Promosi & 2 & 2 & 2 & 2 & 2 \\
\hline Bentuk kemasan & 2 & 3 & 2 & 3 & 3 \\
\hline Variasi ukuran kemasan & 3 & 3 & 2 & 3 & 3 \\
\hline
\end{tabular}




\section{Respon Teknis}

Matriks respon teknis merupakan matriks yang disusun berdasarkan hasil wawancara dengan pemilik perusahaan Tape Handayani 82 tentang tahapan dan faktor-faktor yang mempengaruhi tahapan proses pengolahan suwar suwir Tape Handayani 82 yang digunakan untuk menjawab kebutuhan pelanggan. Terdapat 18 (delapan belas) respon teknis yaitu tingkat kemasakan tape, komposisi bahan baku, tingkat kemasaman, teknik penghalusan, penghilangan serat, komposisi bahan tambahan, teknik pencampuran, lama pencampuran, suhu pemanasan, lama pemanasan, teknik pengadukan, teknik pendinginan, lama pendinginan, jenis alat pemotong, teknik pemotongan, jenis pengemas primer, jenis pengemas sekunder, dan teknik pengemasan.

\section{Matriks Perencanaan \\ a. Target (Goal)}

Goal merupakan target yang ingin dicapai oleh perusahaan dalam memenuhi harapan pelanggan. Nilai goal diperoleh dari nilai tertinggi dari perbandingan tingkat kepuasan pelanggan terhadap suwar suwir produksi Tape Handayani 82 dengan 3 produk pesaingnya yaitu Primadona, Sumber Madu, dan Mutiara Rasa seperti ditunjukkan pada Tabel 3.

Berdasarkan Tabel 3 terdapat 7 (tujuh) atribut mutu dari suwar suwir produksi Tape Handayani 82 yang belum memenuhi target atau harapan pelanggan yaitu komposisi tetap, adanya label komposisi, kesesuaian produk dengan label, umur simpan, tekstur yang tidak berubah, adanya nomor layanan, dan bentuk kemasan. Peningkatan untuk atribut mutu komposisi tetap dapat dilakukan dengan cara mempertahankan komposisi

Tabel 4. Nilai bobot absolut (raw weight) produk suwar suwir Tape Handayani 82

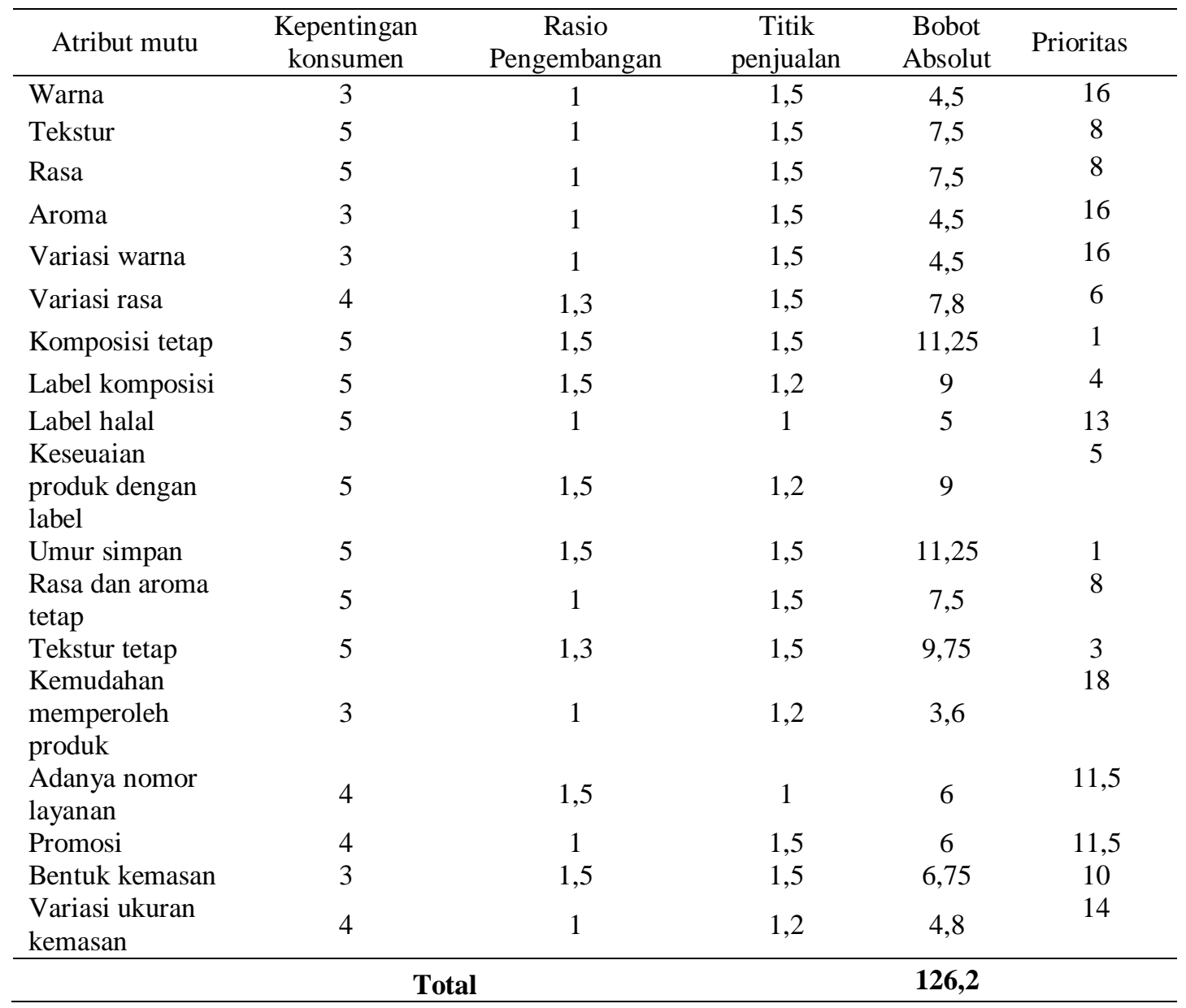


bahan -bahan yang digunakan dalam membuat suwar suwir. Dengan mempertahankan komposisi bahan secara tidak langsung umur simpan dari suwar suwir juga akan tetap terjaga.

\section{Nilai Bobot Absolut (Raw Weight)}

Raw weight merupakan nilai pembobotan yang diberikan pada suatu atribut produk. Menurut Day (1993), suatu atribut mutu dengan nilai raw weight yang besar menyatakan bahwa atribut mutu tersebut harus mendapat prioritas terlebih dahulu untuk diperbaiki.

Nilai raw weight diperoleh dengan cara mengalikan tingkat kepentingan atribut mutu produk dengan nilai improvement ratio dan nilai sales point. Nilai raw weight pada produk suwar suwir Tape Handayani 82 ditunjukkan pada Tabel 4. Atribut mutu produk yang harus diprioritaskan untuk diperbaiki dalam rangka peningkatan kualitas produk adalah pada atribut mutu komposisi tetap dan umur simpan produk.

\section{Matriks Relasi}

Matriks relasi menjelaskan hubungan antara keinginan pelanggan dengan respon teknis yang digambarkan oleh simbolsimbol (Suryaningrat. 2010). Matriks relasi akan memberikan informasi yang dibutuhkan untuk mengoptimalkan proses sehingga harapan pelanggan dapat terpenuhi. Simbol-simbol dan nilai yang diberikan dapat ditunjukkan sebagai berikut :

$$
\begin{aligned}
& O=\text { hubungan kuat }=9 \\
& \bigcirc=\text { hubungan menengah }=3 \\
& \Delta=\text { hubungan lemah }=1
\end{aligned}
$$

Korelasi antara keinginan pelanggan dengan respon teknis yang dinyatakan dengan nilai bobot absolut persyaratan pelanggan dapat dilihat pada Tabel 5 . Nilai bobot abosolut persyaratan pelanggan akan menentukan prioritas perbaikan terhadap respon teknis untuk memenuhi atribut mutu sesuai harapan

\begin{tabular}{|c|c|c|c|c|}
\hline No & Persyaratan teknik & $\begin{array}{c}\text { Bobot } \\
\text { absolut }\end{array}$ & $\begin{array}{c}\text { Prosentase } \\
(100 \%) \\
\end{array}$ & Prioritas \\
\hline 1 & Tingkat kemasakan & 707 & 0,103 & 2 \\
\hline 2 & $\begin{array}{l}\text { Komposisi bahan } \\
\text { baku } \\
\text { Tingkat }\end{array}$ & 708 & 0,103 & 3 \\
\hline 3 & $\begin{array}{l}\text { kemasaman } \\
\text { Teknik }\end{array}$ & 622 & 0,091 & 4 \\
\hline 4 & penghalusan & 394 & 0,058 & 9 \\
\hline 5 & Penghilangan serat & 129 & 0,019 & 14 \\
\hline 6 & $\begin{array}{l}\text { Komposisi bahan } \\
\text { tambahan } \\
\text { Teknik }\end{array}$ & 802 & 0,117 & 1 \\
\hline 7 & $\begin{array}{l}\text { pencampuran } \\
\text { Waktu }\end{array}$ & 343 & 0,050 & 11 \\
\hline 8 & pencampuran & 334 & 0,049 & 12 \\
\hline 9 & Suhu pemanasan & 537 & 0,078 & 5 \\
\hline 10 & Waktu pemanasan & 536 & 0,078 & 6 \\
\hline 11 & $\begin{array}{l}\text { Teknik pengadukan } \\
\text { Teknik }\end{array}$ & 487 & 0,071 & 7 \\
\hline 12 & pendinginan & 18 & 0,003 & 18 \\
\hline 13 & $\begin{array}{l}\text { Waktu pendinginan } \\
\text { Jenis alat }\end{array}$ & 169 & 0,025 & 13 \\
\hline 14 & $\begin{array}{l}\text { pemotong } \\
\text { Teknik }\end{array}$ & 91 & 0,013 & 16 \\
\hline 15 & $\begin{array}{l}\text { pemotongan } \\
\text { Jenis pengemas }\end{array}$ & 19 & 0,003 & 17 \\
\hline 16 & $\begin{array}{l}\text { primer } \\
\text { Jenis pengemas }\end{array}$ & 468 & 0,068 & 8 \\
\hline 17 & $\begin{array}{l}\text { sekunder } \\
\text { Teknik }\end{array}$ & 379 & 0,055 & 10 \\
\hline 18 & pengemasan & 104 & 0,015 & 15 \\
\hline \multicolumn{2}{|c|}{ Total bobot absolut } & 6847 & & \\
\hline
\end{tabular}
pelanggan.

Tabel 5. Nilai bobot absolut persyaratan pelanggan

Respon teknis yang mendapat prioritas tertinggi untuk diperbaiki adalah pada proses penambahan bahan tambahan pada produk suwar suwir. Hal ini disebabkan oleh karena berkaitan dengan variasi rasa dan yang lebih variatif untuk menghindari kejenuhan dengan rasa dan aroma yang tetap sama.

\section{Korelasi Respon Teknis}

Korelasi respon teknis menunjukkan korelasi antara persyaratan teknis yang satu dengan persyaratan - persyaratan lainnya yang terdapat pada matriks. 
Korelasi anatara kedua persyaratan teknis tersebut ditunjukkan dengan menggunakan simbol - simbol sebagai berikut :

- = hubungan kuat positif

$\mathrm{O}=$ hubungan lemah positif

$\Delta=$ hubungan kuat negatif

$\Delta=$ hubungan lemah negatif

( ) = tidak memiliki hubungan.

Yang memiliki hubungan kuat positif antara respon teknis adalah sebagai berikut.

a. Tingkat Kemasakan $\quad-$ Tingkat Kemasaman

Tingkat kemasakan pada tape berpengaruh pada tingkat kemasaman tape. Semakin masak tape berarti fermentasi yang berlangsung semakin lama dan hal ini akan menyebabkan peningkatan rasa masam pada tape sebagai salah satu hasil fermentasi;

b. Teknik Penghalusan - Penghilangan Serat

Teknik penghalusan mempengaruhi proses penghilangan serat pada tape sebagai salah satu bahan baku utama dalam pembuatan suwar suwir. Proses penghalusan secara manual menggunakan tangan akan banyak membuang serat pada tape dibandingkan jika menggunakan mesin;

\section{c. Teknik Pencampuran - Lama Pencampuran}

Teknik pencampuran secara manual yaitu dengan pengadukan membutuhkan ketelitian yang cukup tinggi dari pekerja untuk menentukan semua bahan telah tercampur dengan baik dan merata;

d. Suhu Pemanasan - Lama Pemanasan

Suhu pemanasan atau pemasakan suwar suwir akan mempengaruhi lama pemanasan. Semakin tinggi suhu pemanasan makan akan semakin cepat pula proses pemanasan atau pemasakan suwar suwir;

e. Suhu Pemanasan - Teknik Pengadukan

Suhu pemanasan yang digunakan dapat dipengaruhioleh teknik pengadukan yang digunakan. Penggunaan mesin pengaduk adonan suwar suwir umumnya memiliki pengatur suhu sehingga suhu pemanasan lebih mudah terkendali;

f. Teknik pendinginan -
$\begin{gathered}\text { Pendinginan } \\ \text { Teknik }\end{gathered}$ mempengaruhi lama pendinginan dari adonan suwar suwir yang telah dimasak. Penggunaan mesin pendingin akan dapat mempercepat proses pendinginan dan secara langsung mempercepat pula proses pencetakan;

g. Teknik Pemotongan - Jenis Alat Pemotong

Teknik pemotongan pada proses pencetakan suwar suwir akan menentukan pula jenis alat pemotong yang digunakan;

h. Jenis Bahan Primer - Teknik Pengemasan

Pengunaan jenis bahan pengemas primer sebagai pelindung dari produk suwar suwir dapat mempengaruhi teknik pengemasan pada suwar suwir. Ummnya suwar suwir masih menngunakan plasik sebagai pembungkus primer dan menggunakan teknik pengemasan seara tradisional dengan cara dibungkus;

i. Jenis Bahan Sekunder - Teknik Pengemasan

Penggunaan jenis pengemas sekunder juga akan berpengaruh pada penggunaan teknik pengemasan. Semakin bagus bahan pengemas sekunder yang digunakan maka akan semakin canggih teknik pengemasan yang dapat diterapkan.

\section{Matriks Teknik (Technical Matrix)}

a. Kontribusi (Contribution)

Kontribusi menentukan prioritas dari respon teknis yang diberikan oleh produsen untuk menjawab keinginan pelanggan. Nilai kontribusi menunjukkan kekuatan respon teknis pada keseluruhan atribut produk yang memenuhi kepuasan/harapan pelanggan. Nilai kontribusi didasarkan pada hubungan respon teknis dan kebutuhan pelanggan. Nilai kontribusi dapat dilihat pada Tabel 6. 
Tabel 6. Nilai total kontribusi terhadap respon teknis suwar suwir Tape Handayani 82

\begin{tabular}{lc}
\hline $\begin{array}{l}\text { Hubungan antara respon } \\
\text { teknis dengan kebutuhan } \\
\text { konsumen }\end{array}$ & $\begin{array}{l}\text { Nilai } \\
\text { kontribusi } \\
\text { respon teknis }\end{array}$ \\
\hline Tingkat kemasakan & 4,694 \\
Komposisi bahan baku & 6,622 \\
Tingkat kemasaman & 5,374 \\
Teknik penghalusan & 3,222 \\
Penghilangan serat & 3,08 \\
Komposisi bahan tambahan & 6,578 \\
Teknik pencampuran & 4,36 \\
Waktu pencampuran & 4,612 \\
Suhu pemanasan & 6,556 \\
Waktu pemanasan & 6,748 \\
Teknik pengadukan & 1 \\
Teknik pendinginan & 1 \\
Waktu pendinginan & 1 \\
Jenis alat pemotong & 1 \\
Teknik pemotongan & 1 \\
Jenis pengemas primer & 1,728 \\
Jenis pengemas sekunder & 1,728 \\
Teknik pengemasan & 1,728 \\
\hline
\end{tabular}

Terdapat 4 (empat) respon teknis yang memiliki nilai kontibusi yang lebih tinggi dibandingkan dengan nilai kontribusi dari respon teknis yang lain yaitu lama pemanasan, komposisi bahan baku, suhu pemanasan, dan adanya bahan tambahan pada adonan suwar suwir. Keempat respon teknis tersebut memegang peranan penting dalam upaya pemenuhan kebutuhan pelanggan.

Waktu pemanasan atau pemasakan adonan suwar suwir yang tepat (sekitar 3 jam) akan menghasilkan suwar suwir yang baik. Kriterianya terutama terkait warna, rasa, aroma dan tekstur suwar suwir.

Waktu pemanasan yang terlalu cepat (kurang dari 3 jam) akan menghasilkan tekstur dengan kualitas yang kurang baik. Warna tidak terbentuk secara sempurna akibat proses karamelisasi yang tidak terjadi secara keseluruhan, rasa yang kurang manis akibat gula yang belum bercampur secara merata dan tekstur yang masih lembek/lunak akibat kadar air pada adonan yang belum menguap semua.

Dan apabila waktu pemanasan terlalu lama (lebih dari 3 jam) juga akan menghasilkan adonan suwar suwir dengan kualitas yang kurang baik pula. Warna akan menjadi lebih gosong, akan timbul aroma gosong serta tekstur suwar suwir yang terlalu keras.

Tape dan gula sebagai bahan baku utama dalam proes pembuatan suwar suwir memegang peranan yang sangat penting dalam pemenuhan kebutuhan pelanggan. Suwar suwir yang dibuat dengan perbandingan antara tape dan gula yang seimbang akan menghasilkan produk suwar suwir yang memiliki rasa yang manis, legit dan sedikit asam, membentuk warna suwar suwir menjadi kecoklatan akan tetapi terlihat cerah, dan membentuk tekstur suwar suwir yang padat, lembut pada saat dimakan, serta membentuk aroma suwarsuwir yang khas yaitu aroma karamel gula dan asam.

Seperti halnya lama pemanasan, suhu pemanasan juga harus diatur sedemikian rupa agar suhu yang digunakan tidak terlalu tinggi. Pengaturan suhu dilakukan untuk mencegah terjadinya kegosongan pada adonan yang akan mempengaruhi beberapa atribut mutu seperti warna, rasa, aroma dan tekstur.

Pemberian bahan tambahan pada adonan suwar suwir juga merupakan respon teknis yang cukup penting. Penambahan ini bertujuan untuk memperbaiki dan meningkatkan kualitas beberapa aribut mutu seperti penambahan susu dan perisa makanan dapat meningkatkan rasa dan memperbanyak variasi rasa pada produk suwar suwir;

b. Patok Duga (Benchmarking)

Patok duga (bencmarking) merupakan cara untuk mengetahui tingkat respon teknis yang dilakukan oleh produk pesaing. Nilai bencmarking suwar suwir tape handayani 82 dan 3 produk pesaingnya yaitu suwar suwir Primadona, suwar suwir Sari Madu dan suwar suwir Mutiara Rasa dapat dilihat pada Tabel 7. 
Tabel 7. Nilai patok duga (benchmarking) suwar suwir

\begin{tabular}{lcccc}
\hline \multicolumn{1}{c}{ Respon Teknis } & $\begin{array}{c}\text { Tape } \\
\text { Handay } \\
\text { ani } 82\end{array}$ & $\begin{array}{c}\text { Prima } \\
\text {-dona }\end{array}$ & $\begin{array}{c}\text { Sari } \\
\text { Madu }\end{array}$ & $\begin{array}{c}\text { Mutia } \\
\text {-ra }\end{array}$ \\
\hline $\begin{array}{l}\text { Tingkat } \\
\text { kemasakan tape }\end{array}$ & 2,763 & 2,863 & 2.900 & 2,963 \\
$\begin{array}{l}\text { Komposisi bahan } \\
\text { baku }\end{array}$ & 2,664 & 2,864 & 2,855 & 2,955 \\
$\begin{array}{l}\text { Tingkat } \\
\text { kemasaman }\end{array}$ & 2,570 & 2,826 & 2,884 & 2,942 \\
$\begin{array}{l}\text { Teknik } \\
\text { penghalusan }\end{array}$ & 2,685 & 2,944 & 2,815 & 2,907 \\
$\begin{array}{l}\text { penghilangan } \\
\text { serat }\end{array}$ & 2,712 & 2,942 & 2,808 & 2,904 \\
$\begin{array}{l}\text { Komposisi bahan } \\
\text { tambahan }\end{array}$ & 2,563 & 2,759 & 2,804 & 2,902 \\
$\begin{array}{l}\text { Teknik } \\
\text { pencampuran }\end{array}$ & 2,544 & 2,868 & 2,853 & 2,926 \\
$\begin{array}{l}\text { Lama } \\
\text { pencampuran }\end{array}$ & 2,419 & 2,635 & 2,784 & 2,851 \\
$\begin{array}{l}\text { Suhu pemanasan } \\
\text { lama pemanasan }\end{array}$ & 2,609 & 2,864 & 2,800 & 2,900 \\
$\begin{array}{l}\text { Teknik } \\
\text { pengadukan }\end{array}$ & 2,555 & 2,755 & 2,855 & 2,900 \\
$\begin{array}{l}\text { Teknik } \\
\text { pendinginan }\end{array}$ & 2,722 & 2,667 & 2,833 \\
$\begin{array}{l}\text { lama Pendinginan } \\
\text { Jenis alat } \\
\text { pemotong }\end{array}$ & 2,500 & 2,722 & 2,667 & 2,833 \\
$\begin{array}{l}\text { Teknik } \\
\text { pemotongan }\end{array}$ & 2,500 & 2,722 & 2,667 & 2,833 \\
$\begin{array}{l}\text { Jenis pengemas } \\
\text { primer }\end{array}$ & 2,500 & 2,853 & 2,353 & 2,912 \\
$\begin{array}{l}\text { Jenis pengemas } \\
\text { sekunder }\end{array}$ & 2,500 & 2,853 & 2,353 & 2,912 \\
$\begin{array}{l}\text { Teknik } \\
\text { pengemasan }\end{array}$ & 2,500 & 2,853 & 2,353 & 2,912 \\
\hline & 2,722 & 2,667 & 2,833 \\
& 2,667 & 2,833 \\
& 2,500 & & & \\
\hline
\end{tabular}

Nilai benchmarking dari produk suwar suwir Tape Handayani 82 lebih kecil dibandingkan dengan nilai bencmarking ketiga produk pesaingnya. Hal ini berarti bahwa proses perbaikan dan peningkatan kualitas produk guna memenuhi harapan pelanggan yang dilakukan oleh produsen suwar suwir Tape Handayani 82 kurang baik dan kurang berkesinambungan dibandingkan ketiga produk pesaingnya. Jika nilai bencmarking ketiga produk pesaing dibandingkan, maka suwar suwir produksi Mutiara Rasa memiliki nilai benchmarking yang paling tinggi, dan hal ini berarti bahwa proses perbaikan dan peningkatan kualitas produk guna memenuhi harapan pelanggan yang dilakukan oleh produsen suwar suwir Mutiara Rasa lebih baik dan berkesinambungan dibandingkan kedua produk pesaingnya lainnya.

\section{c. Target (Targetting)}

Targetting adalah tujuan yang ingin dicapai oleh perusahaan untuk memenuhi tingkat kepuasan pelanggan dengan menggunakan respon teknis. Nilai targetting ditentukan berdasarkan nilai benchmarking tertinggi pada produk suwar suwir Tape Handayani 82 dan 3 produk pesaing yaitu suwar suwir Primadona, Suwar suwir Sari Madu dan Suwar Suwir Mutiara Rasa. Tabel 8 menunjukkan nilai targetting terhadap respon teknis produk Suwar suwir Tape Handayani 82.

Tabel 8. Nilai target terhadap respon teknis suwar suwir Tape Handayani 82

\begin{tabular}{|c|c|c|c|}
\hline No & Respon Teknis & $\begin{array}{l}\text { Nilai patok duga } \\
\text { Suwar suwir } \\
\text { Tape Handayani } \\
82\end{array}$ & Target \\
\hline 1 & $\begin{array}{l}\text { Tingkat kemasakan } \\
\text { tape }\end{array}$ & 2,763 & 2,963 \\
\hline 2 & $\begin{array}{l}\text { Komposisi bahan } \\
\text { baku }\end{array}$ & 2,664 & 2,955 \\
\hline 3 & Tingkat kemasaman & 2,570 & 2,942 \\
\hline 4 & Teknik penghalusan & 2,685 & 2,944 \\
\hline 5 & penghilangan serat & 2,712 & 2,942 \\
\hline 6 & $\begin{array}{l}\text { Komposisi bahan } \\
\text { tambahan }\end{array}$ & 2,563 & 2,902 \\
\hline 7 & $\begin{array}{l}\text { Teknik } \\
\text { pencampuran }\end{array}$ & 2,544 & 2,926 \\
\hline 8 & $\begin{array}{l}\text { Waktu } \\
\text { pencampuran }\end{array}$ & 2,419 & 2,851 \\
\hline 9 & Suhu pemanasan & 2,609 & 2,900 \\
\hline 10 & Waktu pemanasan & 2,555 & 2,900 \\
\hline 11 & Teknik pengadukan & 2,500 & 2,833 \\
\hline 12 & Teknik pendinginan & 2,500 & 2,833 \\
\hline 13 & Waktu Pendinginan & 2,500 & 2,833 \\
\hline 14 & Jenis alat pemotong & 2,500 & 2,833 \\
\hline 15 & Teknik pemotongan & 2,500 & 2,833 \\
\hline 16 & $\begin{array}{l}\text { Jenis pengemas } \\
\text { primer }\end{array}$ & 2,500 & 2,912 \\
\hline 17 & $\begin{array}{l}\text { Jenis pengemas } \\
\text { sekunder }\end{array}$ & 2,500 & 2,912 \\
\hline 18 & Teknik pengemasan & 2,500 & 2,912 \\
\hline
\end{tabular}


Nilai targetting ditentukan berdasarkan nilai benchmarking tertinggi pada produk suwar suwir Tape Handayani 82 dan 3 produk pesaing yaitu suwar suwir Primadona, Suwar suwir Sari Madu dan Suwar Suwir Mutiara Rasa. Nilai target suwar suwir Tape Handayani 82 lebih rendah daripada nilai target yang ingin dicapai. Hal ini menunjukkan bahwa produk suwar suwir Tape Handayani 82 belum memenuhi target dalam upaya untuk pemenuhan kualitas suwar suwir guna menjawab keinginan pelanggan sehingga masih diperlukan perbaikan- perbaikan pada beberapa atribut mutu agar dapat memenuhi harapan pelanggan.

Berdasarkan analisis yang telah dilakukan, maka dapat dilakukan analisis lebih lanjut yaitu mengidentifikasi atribut mutu. Atribut mutu tersebut memiliki nilai tinggi pada prioritas harapan pelanggan dan berstatus harus "diperbaiki", yaitu atribut yang harus diupayakan untuk ditingkatkan kinerjanya sehingga mampu memuaskan pelanggan.

Status "diperbaiki" pada atribut mutu tersebut diperoleh setelah mempertimbangkan nilai benchmarking

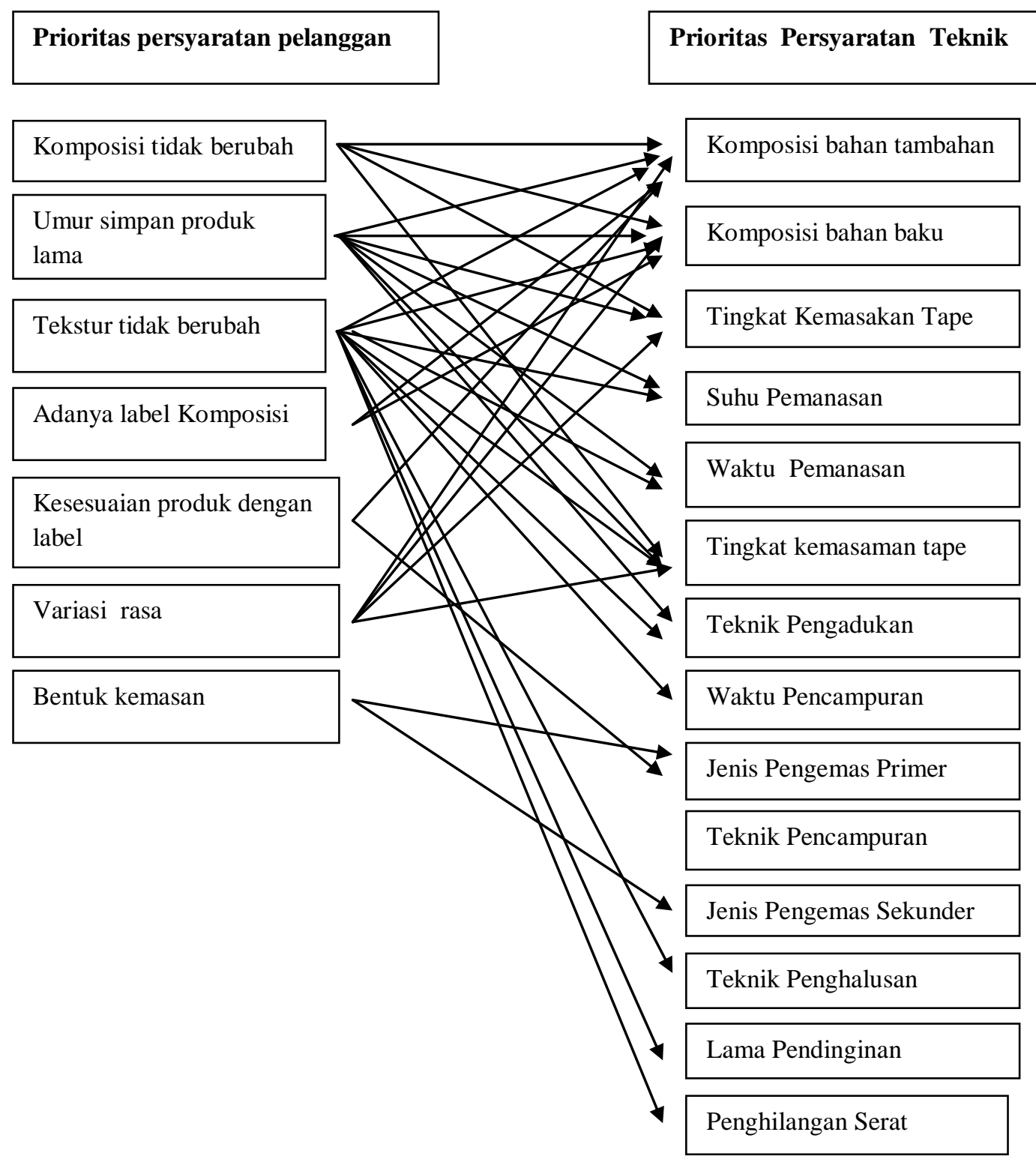

Gambar 1. Keterkaitan atribut mutu dengan status "diperbaiki" dengan persyaratan teknis 
dan faktor skala kenaikan. Status "diperbaiki" diberikan apabila nilai skala kenaikan lebih dari satu dan nilai benchmarking pada atribut mutu tersebut lebih rendah daripada produk pesaing. Atau, jika nilai benchmarking sama, namun nilai skala kenaikannya lebih dari satu dan atribut tersebut mempunyai nilai persyaratan pelanggan yang tinggi, maka diberikan status "diperbaiki".

Perbaikan atribut mutu dengan status "diperbaiki”, dilakukan dengan cara memperbaiki persyaratan teknis yang mempunyai keterkaitan erat dengan atribut mutu yang dimaksud seperti terdapat pada Gambar 1. Prioritas persyaratan pelanggan disusun berdasarkan skala kenaikan lebih dari 1 dan memiliki nilai patok duga yang lebih rendah dibandingkan pesaingnya. Sedangkan prioritas persayaratan teknik disusun berdasarkan urutan nilai bobot absolut dari nilai tertinggi hingga nilai terendah.

Berdasarkan Gambar 1, atribut mutu yang merupakan prioritas persyaratan pelanggan pertama yang harus diperbaiki adalah komposisi tetap. Atribut mutu ini dapat diperbaiki dengan cara memperbaiki persyaratan teknik yaitu penggunaan komposisi bahan tambahan yang tetap, komposisi bahan baku yaitu komposisi tape dan gula sebagai bahan baku utama, tingkat kemasakan dan tingkat kemasaman tape.

Atribut mutu berikutnya yang harus diperbaiki adalah umur simpan produk yang lama. Peningkatan atribut mutu ini dapat dilakukan dengan cara memperbaiki beberapa respon teknis yaitu komposisi bahan tambahan, komposisi bahan baku, tingkat kemasakan tape, suhu pemanasan, waktu pemanasan, tingkat kemasaman tape dan teknik pengadukan.

Terdapat 14 (Empat belas) persyaratan teknis tersebut yang dijabarkan untuk mengetahui faktor-faktor utama yang mempunyai pengaruh terhadap delapan atribut mutu yang "diperbaiki". Identifikasi faktor utama dapat dilakukan dengan bantuan diagram sebab tulang ikan (fishbone) (Gambar 2). Faktor utama merupakan respon teknis yang berpengaruh terhadap peningkatan suatu atribut mutu.

Atribut mutu yang merupakan prioritas pertama yang harus diperbaiki yaitu komposisi tidak mudah berubah, maka persyaratan teknis yang harus

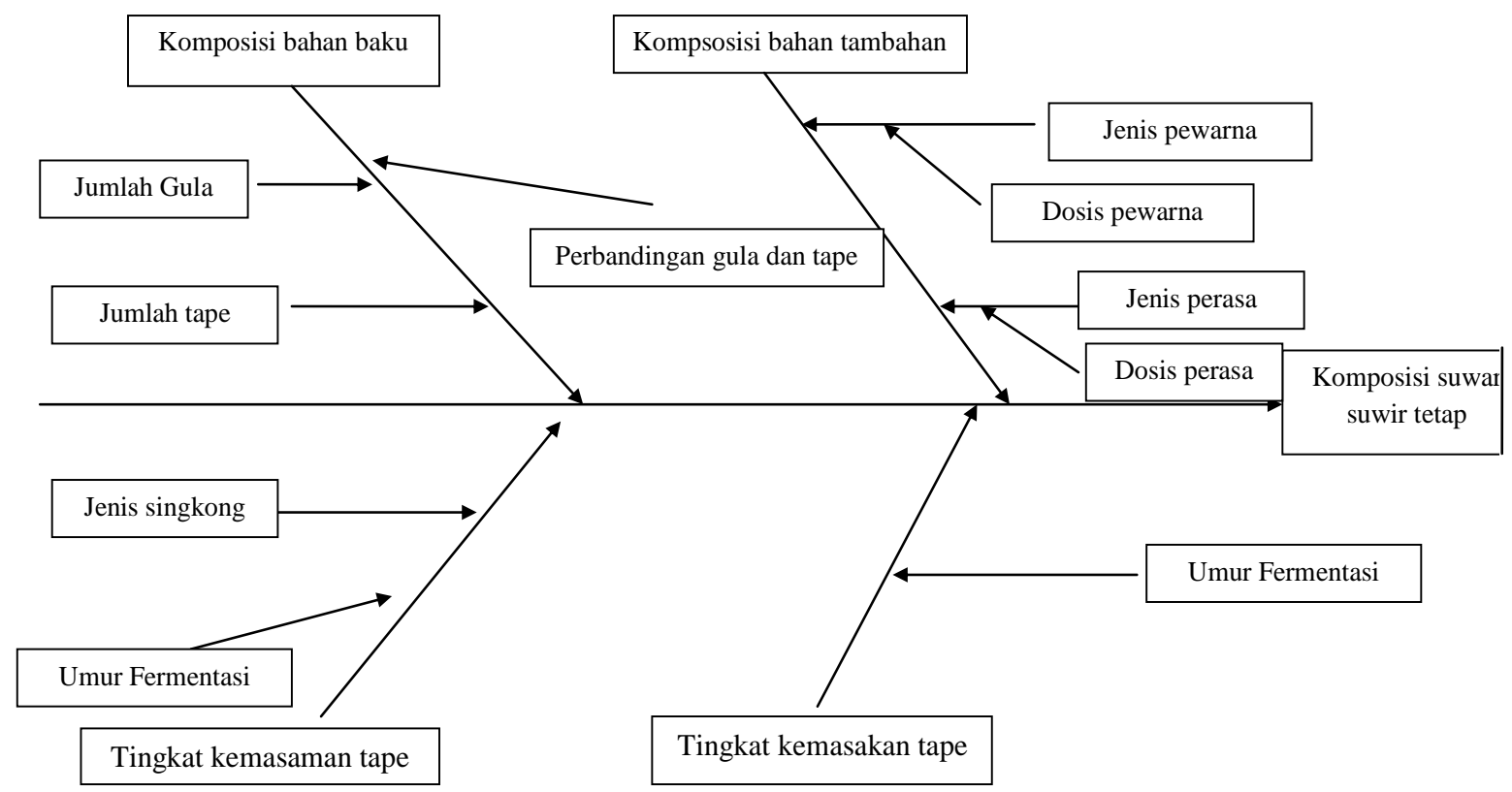

Gambar 2. Diagram sebab akibat antara atribut mutu "komposisi tidak berubah" dengan respon teknis yang mempengaruhi 


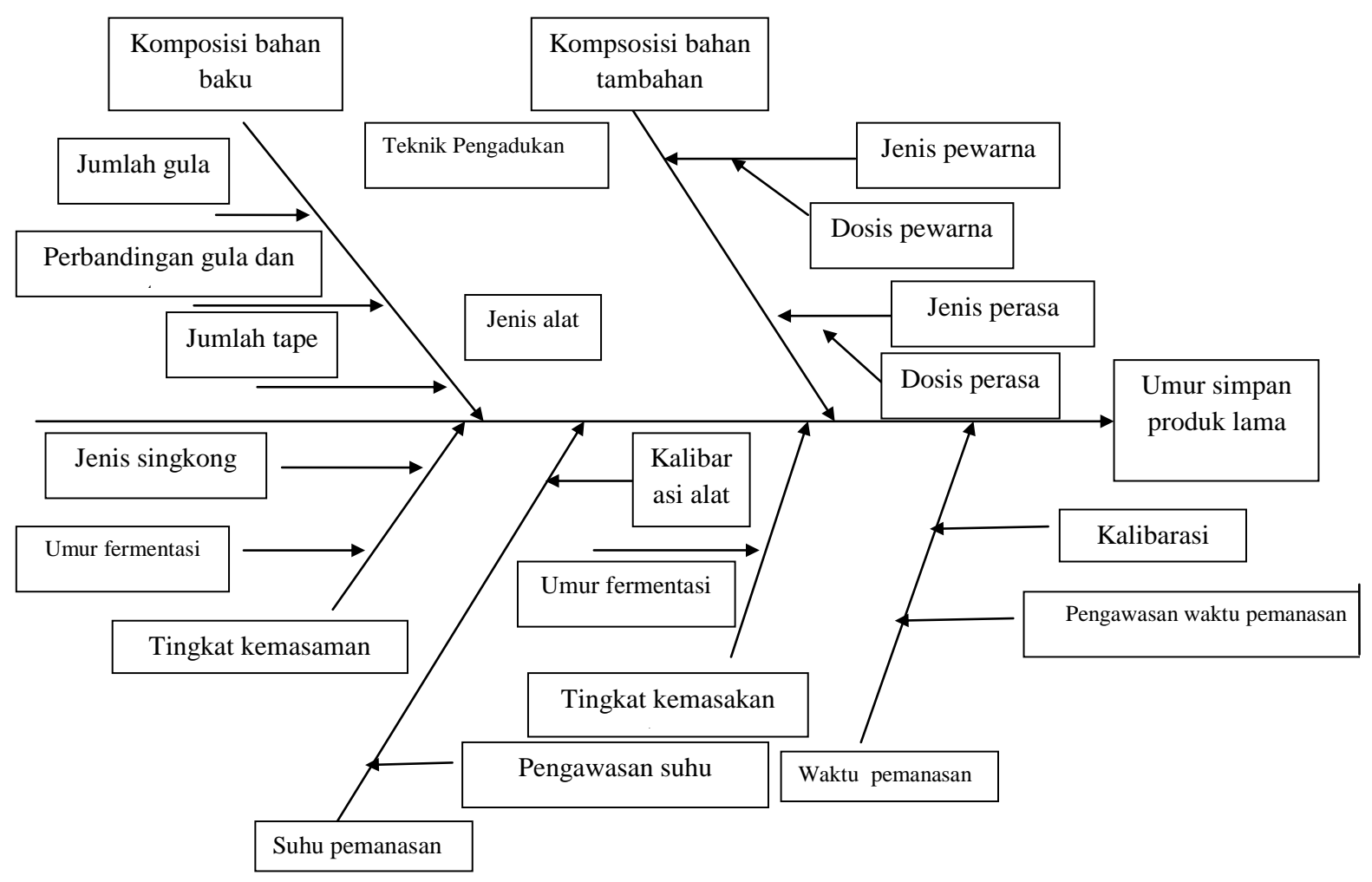

Gambar 3. Diagram sebab akibat antara atribut mutu "umur simpan produk" dengan respon teknis yang mempengaruhi

diperbaiki adalah komposisi bahan tambahan, komposisi bahan baku, tingkat kemasakan dan tingkat kemasaman. Identifikasi pada faktor komposisi bahan tambahan adalah jenis bahan tambahan, dosis bahan tambahan, Pada faktor komposisi bahan baku lebih difokuskan dengan perbandingan penggunaan bahan baku utama yaitu gula dan tape. Identifikasi pada faktor proses dilakukan dengan cara pengendalian terhadap tingkat kemasakan bahan baku suwar suwir. Identifikasi pada faktor manusia dapat dilakukan dengan pengawasan yang dilakukan selama proes penambahan bahan tambahan. Perbaikan persyaratan teknis selanjutnya dapat dilihat pada Gambar 2.

Perbaikan atribut mutu selanjutnya yang menempati prioritas kedua adalah umur simpan produk yang lama. Perbaikan atribut mutu ini dapat dilakukan dengan memperbaiki tujuh respon teknis yaitu komposisi bahan baku, komposisi bahan tambahan, tingkat kemasakan tape, tingkat kemasaman tape, suhu pemanasan, lama pemanasan dan teknik pengadukan seperti pada Gambar 3.

\section{KESIMPULAN}

Terdapat 7 (tujuh) atribut mutu suwar suwir Tape Handayani 82 yang diharapkan oleh pelanggan untuk mendapatkan prioritas peningkatan mutu yaitu komposisi tetap, umur simpan produk, tekstur tidak berubah, adanya label komposisi, kesesuian produk dengan label, variasi rasa, bentuk kemasan. Respon teknis yang memerlukan perbaikan untuk peningkatan mutu sesuai harapan pelanggan adalah komposisi bahan tambahan, komposisi bahan baku, tingkat kemasakan, suhu pemanasan, waktu pemanasan, tingkat kemasaman, teknik pengadukan, waktu pencampuran, jenis pengemas primer, teknik pencampuran, jenis pengemas sekunder, teknik penghalusan, waktu pendinginan, dan penghilangan serat. 


\section{DAFTAR PUSTAKA}

Abdullah, T., Tantri, F. 2012. Manajemen Pemasaran. PT Raya Grafindo Persada, Jakarta.

Day. 1993. Quality Function Deployment Lingking a Company With Its Customer. ASQC Qualitu Press: Milwaukee.is Consin USA

Dwi SI, Ruriani E, Nafi A. 2012. Aplikasi metode quality function deployment (QFD) untuk pengembangan mutu roti manis berbahan baku mocaf. Berkala Ilmiah Pertanian, 10 (10): 1-4.

Garvin, D.A. 1987. Competing On The Eight Dimensions of Quality. Harvard Business Review No 87603

Magutu PO. 2010. Business process reengineering for competitive advantage. African Journal of Business \& Management (AJBUMA), 1 (16): 3542.

Nasution, M. N. 2001. Manajemen Mutu Terpadu. Ghalia Indonesia, Bogor.

Suryaningrat, I.B, Djumarti, Ruriani E, Kurniawati I. 2010. Aplikasi quality function deployment (QFD) untuk peningkatan kualitas produk mie jagung. Agrotekologi, 4 (1): 8- 7

Suryaningrat, I.B. 2013. Application of quality function deployment $(Q F D)$ for quality improvement of suwar suwir product. Agroindutrial Journal, 2 (1): 55-61.

Tjiptono F, Diana A. 2005. Total Quality Management. Andi Offset, Yogyakarta.

UNIDO [United Nations Industrial Development Organization]. 2006. A Guide for Small and Medium-Sized Enterprises [Working Paper]. United Nations Industrial Development Organization, Vienna. 